East African Medical Journal Vol. 86 No. 4 April 2009

CANCER OF THE PENIS: CASE REPORT

D. K. Kiptoon, MBChB, MMed (Surg), Consultant Surgeon, Meru District Hospital, P.O. Box 16-00202, Nairobi, Kenya, P. M. Ngugi, MBChB, MMed (Surg), Cert Urol. (Royal Coll. Surg. of Engl), Senior Lecturer, Department of Surgery, College of Health Sciences, University of Nairobi, P.O. Box 19786-00202, Nairobi, Kenya and F. S. Rana, MBChB, MMed (Path), Assistant Professor of Anatomic Pathology, Department of Pathology, Aga Khan University Hospital, P. O. Box 30270-00100, Nairobi, Kenya

Request for reprints to: Dr. D. K. Kiptoon, P. O. Box 16-00200, Nairobi, Kenya

\title{
CANCER OF THE PENIS: CASE REPORT
}

\author{
D. K. KIPTOON, P. M. NGUGI and F. S. RANA
}

\begin{abstract}
SUMMARY
Two patients with penile carcinoma are presented after management at a district hospital in Kenya. Both had undergone ritual circumcision as teenagers and presented late. HR was a 73 year old who presented with a fungating penile mass for which a partial penectomy was performed after wedge biopsy confirmed malignancy. He thereafter declined to have the surgical specimen sent for histology and took the amputated stump for burial in his compound to avoid bad omen. GK was 25 years old and presented with a fungating mass and underwent partial penectomy after a histological diagnosis was made. He absconded from follow-up after being informed of the need for further surgery due to tumour infiltration of the surgical margins. The history and clinical images are presented and we discuss the difficulties of cancer management at a rural district hospital.
\end{abstract}

\section{INTRODUCTION}

Carcinoma of the penis is an uncommon disease affecting less than $1 \%$ of the male adult population (1). It is possible that hygiene plays an important role in its causation (2). A majority of patients present late with advanced disease (3). We present two patients with late penile cancer who were managed in Meru District Hospital.

\section{CASE REPORT}

Case 1: HR was a seventy three year old who presented with a one year history of a growth on the glans penis. He was previously well then noted a painless, progressive growth on the glans penis which was of insidious onset. After about six months, as the lesion grew larger, there was associated foul smell and a purulent discharge. He also noted bilateral inguinal swellings over the last four months, which were initially painful but were painless at the time of presentation.

He had no problem with micturition. He gave no history of haematuria or of preceding sexually transmitted infection. There was also no history of penile pruritus or any scrotal mass. He had undergone ritual circumcision when he was a teenager and thereafter had had no problem with his genitalia. His past medical history was not contributory. He was a farmer married with five children. He gave no history of a similar illness in the family. He had chewed snuff all of his adult life and took moderate amounts of alcohol.

Examination revealed an unkempt elderly man in fair general condition. He was not pale, jaundiced or cyanosed. His vital signs were within normal limits: BP 120/170 $\mathrm{mmHg}$, temperature $37.3^{\circ} \mathrm{C}$, pulse 80 beats/minute and respiratory rate 18 breaths/minute. Local examination showed a large fungating mass which had totality obliterated the glans penis (Figure 1).

Figure 1

Fungating penile mass

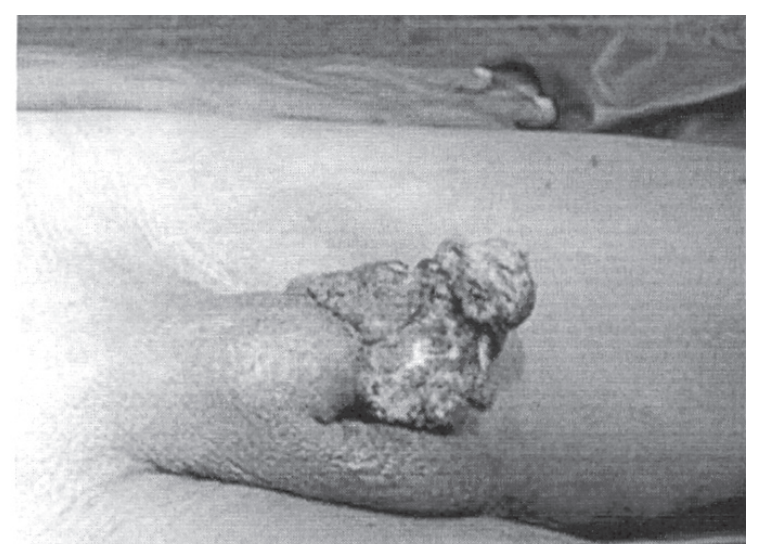

The mass was firm, not tender and had a foul smell with purulent discharge. There were associated multiple large bilateral superficial inguinal nodes which were $2 \times 1 \mathrm{~cm}$, mobile and free. The scrotum and contents were normal. The 
abdomen was scaphoid, moving with respiration, and had no surgical scars or therapeutic marks. There were no areas of tenderness and no palpable intra-abdominal masses. There were normal bowel sounds. Digital rectal examination revealed a normal anal sphincter tone and a moderately enlarged, smooth, firm prostate with the central groove preserved. The rectal mucosa was free over the prostate and there was no blood on the examining finger. Other findings were unremarkable.

An impression of carcinoma of the penis was made.

The following investigations were performed:

(i) Haemogram

$\mathrm{Hb} 12.3 \mathrm{~g} / \mathrm{dl}$

WBC $10 \times 10^{9} / \mathrm{L}$

Platelets $420 \times 10^{9} / \mathrm{L}$

ESR $14 \mathrm{~mm} / \mathrm{h}$

(ii) $\mathrm{U} / \mathrm{E} / \mathrm{C}$

$\mathrm{K}+3.9 \mathrm{mmol} / \mathrm{L}$

$\mathrm{Na}+139 \mathrm{mmol} / \mathrm{L}$

CI- $92 \mathrm{mmol} / \mathrm{L}$

(iii) Urinalysis -Normal

(iv) Random blood sugar $-6.2 \mathrm{mmol} / \mathrm{L}$

(v) Chest radiograph -Normal

(vi) Wedge biopsy-squamous cell carcinoma

The patient was put on parenteral antibiotics for one week to control the sepsis. He was counselled on the need for penile amputation and an informed consent was obtained. Partial penile amputation was performed under general anaesthesia. After draping, a penile tourniquet was applied. The penile skin was circumcised approximately $10 \mathrm{~mm}$. proximal to the tumour and all superficial vessels were identified and ligated (Figure 2).

Figure 2

Division of Corpora

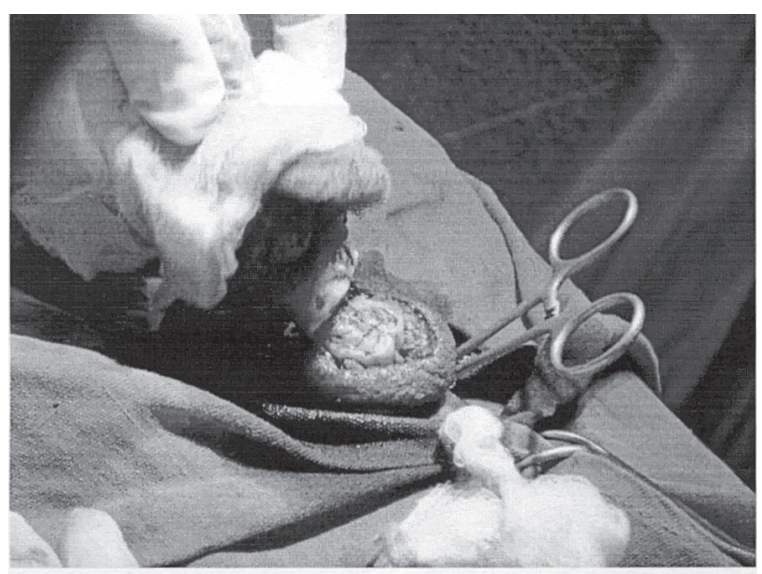

The corpus spongiosum was identified and freed from the corpora cavernosa. The corpora cavernosa were then transected. The corpus spongiosum was then transected. The tourniquet was released and all bleeders controlled. An opening was made on the ventral aspect of the penile stump and the urethra brought out. The corpora cavernosa were closed in two layers. A Foley's catheter was introduced into the urethra and left in situ. A tube drain was inserted and the wound was then closed with $2 / 0$ interrupted braided polyglactin (vicryl) sutures (Figure 3).

Figure 3

End of operation

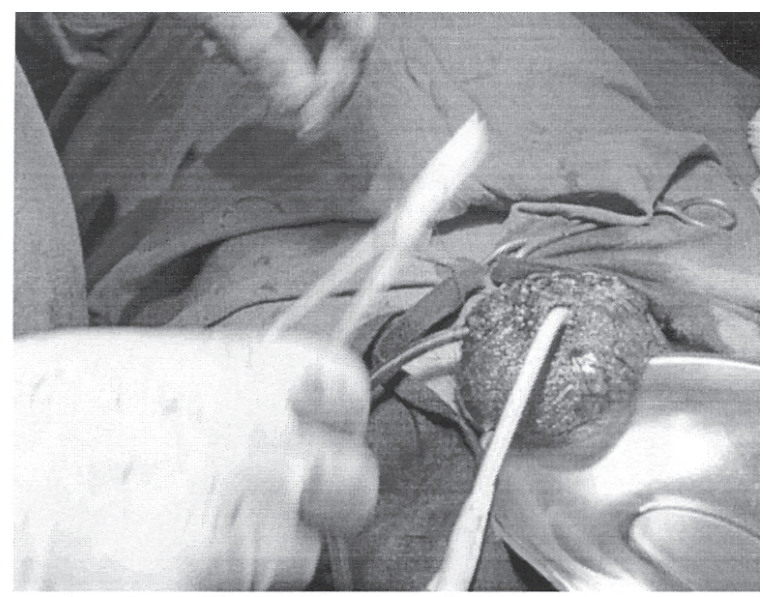

The patient did well post operatively and the Foley's catheter was removed after one week. He was able to void well after removal of the catheter. The wound healed well (Figure 4).

Figure 4

One week post operative

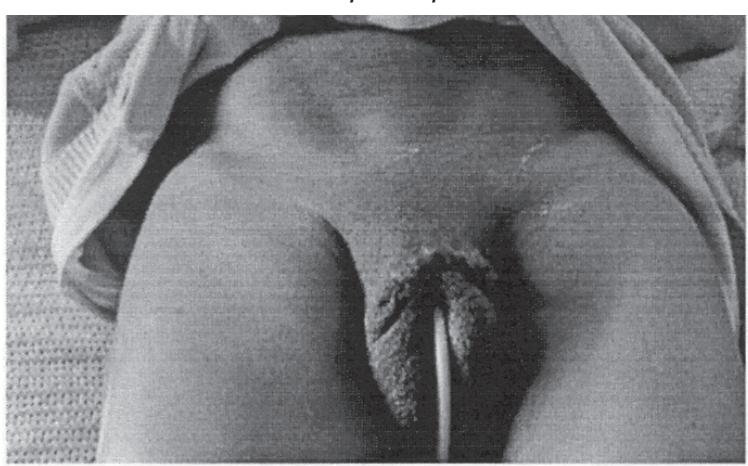

At six weeks follow-up, the inguinal lymphadenopathy had completely regressed. The patient has now been followed for over 30 months postoperatively and has no recurrence (local or inguinal) and is able to void well. The patient burying the specimen precluded postoperative histopathological assessment. This was due to the practice in this hospital of entrusting specimens to patients for transmission to laboratories in Nairobi.

Case 2: GK, twenty five year old, presented to us with a one-year history of a swelling on the glans penis. The swelling was initially a small black 
pruritic plaque-like lesion, which progressively increased in size extending from the glans to the mid-shaft of the penis despite treatment at several dispensaries. There was no history of preceding sexually transmitted infection. He had noted dysuria in the last one month of illness and he reported that his urine stream exited from a point halfway up the shaft of the penis. GK had undergone traditional ritual circumcision at age 14 years. He gave a six year history of cigarette smoking, half a pack a day.
Examination revealed a young man in fair general condition with an exophytic, fungating, ulcerated circumferential mass on the penis extending from the glans to mid-shaft (Figure 5). The edges were rolled over and the base had necrotic slough. He also had bilateral inguinal lymphadenopathy, with firm, nontender, mobile nodes that measured $2-4 \mathrm{~cm}$ in their longest diameter.

Figure 5

Penile lesion on a 25 year old male

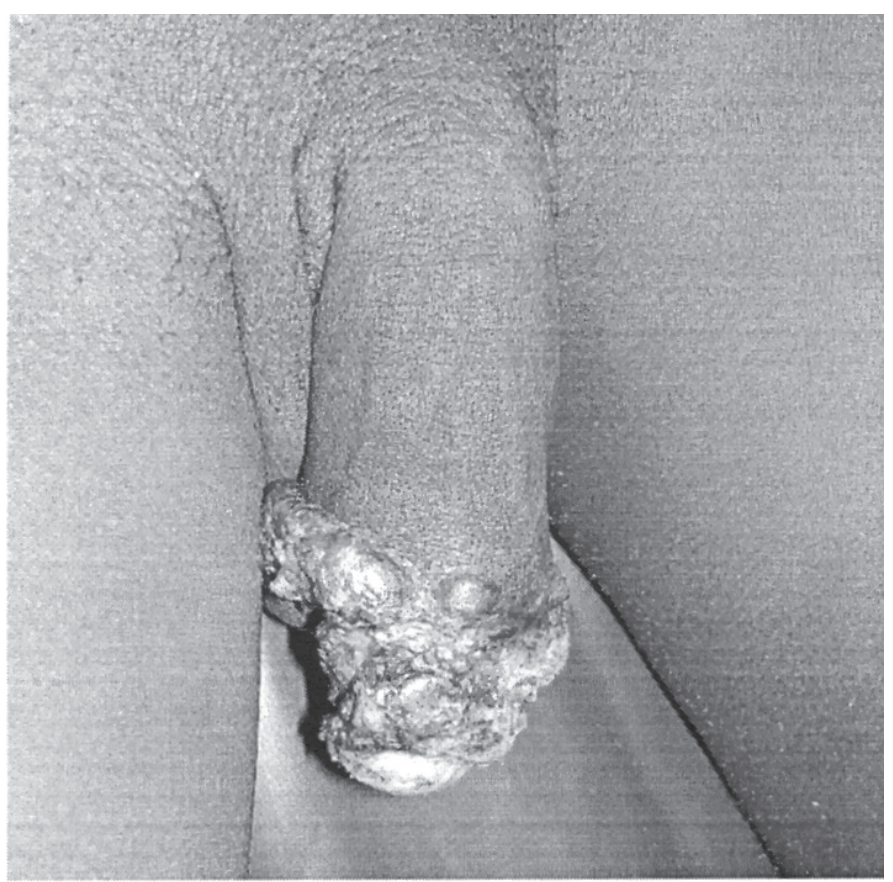

Figure 6

Gross pathological specimen

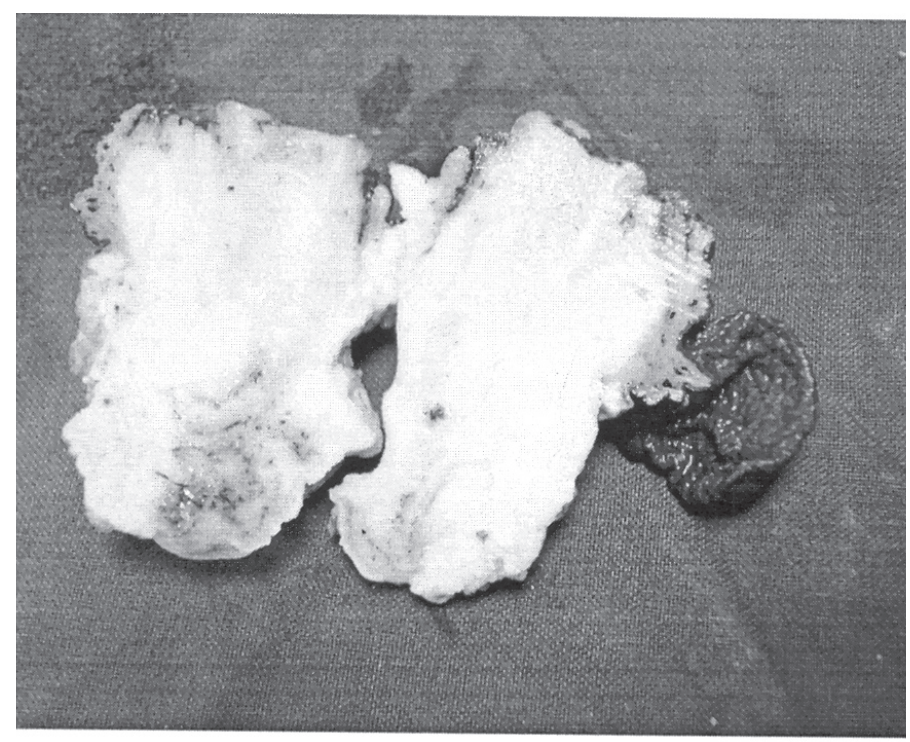


An impression of cancer of the penis was made and confirmed by wedge biopsy as squamous cell carcinoma. Other preoperative investigations were normal $(\mathrm{Hb}-11.3 \mathrm{~g} / \mathrm{dl}$; ELISA for HIVnegative; U/E/C-normal). Partial penectomy and bilateral inguinal lymph node dissection was carried out under general anaesthesia. The wounds healed well postoperatively. Histology showed an ulcerated infiltrating keratinising squamous cell carcinoma extending to the surgical margins (Figures 6 and 7). The lymph nodes were disease free. GK absconded from follow up on being informed of the need for further surgery.

Figure 7

Haematoxyline - eosin stain (0x200)

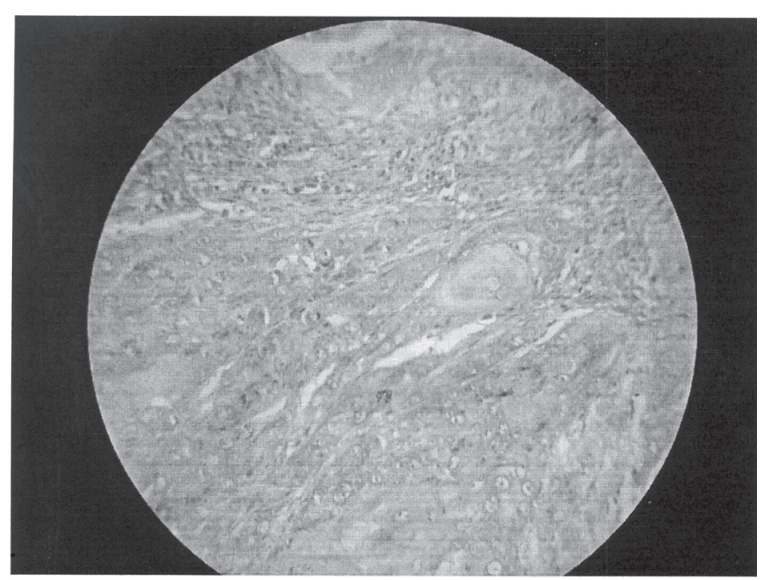

DISCUSSION

Carcinoma of the penis is a relatively uncommon malignancy, accounting for $<1 \%$ of all malignancies in men $(1,3)$. The peak incidence is in the $6^{\text {th }}$ and $7^{\text {th }}$ decades of life (4). The aetiology of cancer of the penis is unclear but certain associated conditions have been implicated, including the presence of a foreskin, chronic inflammatory conditions and exposure to human papilloma virus (5).

There is also a postulated role for poor hygienic standards in causation (6). Although circumcision in neonates is protective, circumcision after adolescence is not protective $(4,7,8-10)$. A history of smoking and infection by human papilloma virus (HPV) are also linked to an increased risk for penile cancer $(10,11)$. A history of phimosis has been found in $25 \%$ of penile cancer patients (12).

Metastases from penile cancers spread by way of the penile lymphatics to regional nodes, specifically the superficial and deep inguinal nodes, and subsequently the external iliac and obturator nodes within the pelvis (13). The presence of inguinal lymph node enlargement does not necessarily imply metastases but could be due to sepsis especially in situations like those that we report in which there is neglect or delay in seeking medical attention (14). However, fineneedle aspiration cytology is recommended before inguinal lymph node dissection is carried out $(15,16)$.

The management of carcinoma of the penis is by partial or total penectomy (16). However, less extensive surgical procedures and radiotherapy in selected cases with early disease can control it with preservation of the phallus (17). A $2 \mathrm{~cm}$ margin has been used in partial penectomy but recent studies show that even a few millimeters of resection margin is oncologically safe (18). The late presentation of our patients is in keeping with findings of other authors that late presentation is to be expected (1). Thus, they were not candidates for phalluspreserving interventions.

The two cases presented highlight the difficulties in provision of surgical care to patients with malignancies in rural district hospitals in Kenya. There were no histopathology services in the institution and patients were given biopsy materials to submit to laboratories in Nairobi. This resulted in the loss of one specimen due to the patient's superstitious beliefs. The other problem peculiar to this setting that is clearly exposed is the difficulty of defaulter tracing. The second patient was lost to follow-up as it was not possible to trace him to his rural home because he provided unclear contact information.

\section{ACKNOWLEDGEMENTS}

To the Medical Superintendent, Meru District Hospital for consent to publish this report. Consent was obtained from the patients to publish the clinical images.

\section{REFERENCES}

1. Magoha, G.A.O. and Kaale, R.F. Epidemiology and clinical aspects of cancer of the penis at Kenyatta National Hospital. East Afr. Med. J. 1995; 72: 359-361.

2. Gursel, E.O., Georgountzos, C., Uson, A.C., et al Penile Cancer. Urol. 1973; 1: 569-578.

3. Magoha, G.A.O. and Ngumi, Z.W.W. Cancer of the penis at Kenyatta National Hospital East. Afr. Med. J. 2000; 77: 526-530.

4. Thomas, L.A. and Small, C.S. Carcinoma of penis in Southern India. J. Urol. 1968; 100:520-526.

5. Kayes, O., Ahmed, H.U., Arya, M. and Minhas, S. Molecular and genetic pathways in penile cancer. Lancet Oncol. 2007; 8: 420-429.

6. Dodge, O.G. and Kaviti, J.N. Male circumcision among the peoples of East Africa and the incidence of genital cancer. East. Afr. Med. J. 1965; 42: 98105. 
7. Kochen, M. and McCurdy, S. Circumcision and the risk of cancer of the penis. A life-table analysis. Am. J. Dis. Child. 1980; 134:484-486.

8. Licklider, S. Jewish penile carcinoma. J. Urol. 1961; 86: 98.

9. Schoen, E.J., Oehrli, M., Colby, C. and Machin, G. Thehighly protective effect of newborn circumcision against invasive penile cancer. Pediatrics. 2000; 105: E36.

10. Maden, C., Sherman, K.J., Beckman, A.M., et al. History of circumcision, medical conditions, and sexual activity and risk of penile cancer. J. Natl. Cancer Inst. 1993; 85: 19-24.

11. Cupp, M.C., Malek, R.S., Goelner, J.R. et al. The detection of human papilloma virus deoxyribonucleic acid in intraepithelial, in situ, verrucous and invasive carcinoma of the penis. J. Urol. 1996; 154: 1024-1029.

12. Tsen, H.F., Morgenstern, H., Mack, T.I. and Peters, R.K. Risk factors for penile cancer: results of a population based case-control study in Los
Angeles County (United States). Cancer Causes Contr. 2001; 12:267-277.

13. Cabanas, R.M. An approach to the treatment of penile carcinoma. Cancer. 1977; 39: 456-466.

14. Mosconi, A.M., Roila, F. and Gatta, G. Cancer of the penis. Critical Reviews in Oncologyl Haemotology 2005; 53:165-177.

15. Saisorn, I., Lawrentschuk, N., Leewansangtong, S. and Bolton, D.M. Fine-needle aspiration cytology predicts inguinal lymph node metastasis without antibiotic pretreatment in penile carcinoma. Brit. J. Urol. Int. 2006; 97: 1225-1228.

16. Magoha, G.A.O. Management of carcinoma of the penis: a review. East Afr. Med. J. 1995; 72: 547-550.

17. Hegarty, P.K., Rees, R.W., Borley, L.C., et al. Contemporary management of penile cancer. Brit. J. Urol. Int. 2008; 102:928-932.

18. Minhas, S., Kayes, O., Hegarty, P.K., et al. What surgical resection margins are required to achieve oncological control in men with primary penile cancer? Brit. J. Urol. Int. 2005; 96: 1040-1043. 